\title{
O GÊNERO HETEROTHALAMUS LESSING E TÁXONES AFINS'
}

\author{
LEONARDO PAZ DEBLE ${ }^{2}$ ANABELA SILVEIRA DE OLIVEIRA ${ }^{3}$ \\ JOSÉ NEWTON CARDOSO MARCHIORI ${ }^{4}$
}

\section{RESUMO}

O gênero Heterothalamus Lessing e táxones afins são estudados com o objetivo de contribuir para o conhecimento da flora sul-americana, em especial do Brasil, Argentina e Uruguai. O gênero Heterothalamulopsis constitui novidade taxonômica. Heterothalamulopsis wagenitzii, única espécie do gênero até o momento, compreende subarbustos dióicos, glandulosos e ramificados, providos de pápus com cerdas persistentes e ápice dilatado nas flores masculinas, e de flores femininas carnosas, de ápice ligulado, protegidas por páleas persistentes; endêmica do sul do Brasil, a espécie tem ocorrência restrita à borda dos "Aparados da Serra Geral", nos estados de Santa Catarina e Rio Grande do Sul. O gênero Heterothalamus compreende três espécies polígamo-dióicas ou imperfeitamente dióicas de subarbustos e arbustos ramificados, glandulosos, que se caracterizam pela presença de 1-2-séries de flores radiais, femininas ou neutras, nos capítulos funcionalmente masculinos, e pela presença de flores carnosas de ápice ligulado nos capítulos femininos, protegidas por páleas persistentes. A distribuição geográfica do gênero inclui o centro da Argentina (províncias de Córdoba, San Luis, La Rioja e Santiago del Estero), o Uruguai e o sul do Brasil (estados do Rio Grande do Sul e Santa Catarina). Foi elaborada uma chave dicotômica para a separação dos gêneros da subtribo Baccharinae Less., incluídos nas floras da Argentina, Uruguai e Brasil. Outra chave é apresentada para a separação das três espécies de Heterothalamus. Baccharis czermakii Hochreutiner foi presentemente reduzido à sinonímia de Heterothalamus psiadioides Lessing.

\section{ABSTRACT}

The genus Heterothalamus Lessing and genera allied are studied, as a contribution to the knowledge of south-american flora, especially from Brazil, Argentina and Uruguay. The genus Heterothalamulopsis is a taxonomic novelty. Heterothalamulopsis wagenitzii, single species of the genus until this moment, is a dioecious small glandulous and ramified shrubs, provided with persistent bristled and broad apex pappus in male flowers, and with ligulate female flowers, protected by persistent paleas. The species, endemic of southern Brazil, occurs only on the border of the "Aparados da Serra Geral", in the states of Rio Grande do $\mathrm{Sul}$ and Santa Catarina. The genus Heterothalamus comprises three polygamo-dioecious or imperfect dioecious species of small glandulous and ramified shrubs, characterized by the presence of 1-2-series of radial, female or neutral flowers, in functional male heads, and by the presence of ligulate flowers, protected with persistent paleas, in female heads. The geographic distribution of the genus includes central Argentina (provinces of Cordoba, San Luis, La Rioja and Santiago del Estero), Uruguay and southern Brazil (states of Rio Grande do Sul and Santa Catarina). It is supplied a key to set apart the genera of subtribe Baccharinae Lessing, found in the brazilian, argentinian and uruguayan floras. Another key is furnished to distinguish the three studied species of Heterothalamus. Baccharis czermackii Hochreutiner was presently reduced to the synonymity of Heterothalamus psiadioides Lessing.

1 Artigo recebido em 29/07/2004 e aceito para publicação em 15/09/2004.

2 Biólogo, Msc., Acadêmico do Programa de Pós-graduação em Engenharia Florestal, Centro de Ciências Rurais, Universidade Federal de Santa Maria, CEP 97105-900, Santa Maria (RS).deble.biol@,bol.com.br

3 Bióloga, Acadêmica do Programa de Pós-graduação em Engenharia Florestal Centro de Ciências Rurais, Universidade Federal de Santa Maria, CEP 97105-900, Santa Maria (RS).anabela.biol@mail.ufsm.br

4 Engenheiro Florestal, Dr., Professor Titular do Departamento de Ciências Florestais, Centro de Ciências Rurais, Universidade Federal de Santa Maria, CEP 97105-900, Santa Maria (RS). marchiori@,ccr.ufsm.br 


\section{INTRODUÇÃO}

Composto de duas espécies, restritas ao sul do Brasil, Uruguai e às serras de Córdoba e San Luis, no centro da Argentina, o gênero Heterothalamus parecia não oferecer novidades, tendo-se em vista publicações recentes sobre as floras regionais. Heterothalamus alienus (Sprengel) O. Kuntze e Heterothalamus psiadioides Lessing, em verdade, separam-se facilmente entre si, bem como das demais espécies da subtribo Baccharinae Lessing (tribo Astereae Cassini), por terem páleas persistentes e flores femininas carnosas, de ápice ligulado. A revisão de exsicatas nos principais herbários da região, bem como novas coletas e observações de material vivo, mostraram, todavia, a necessidade de uma investigação mais profunda do grupo, justificando o presente estudo.

$\mathrm{O}$ gênero Heterothalamus foi descrito por Lessing (1830), que subordinou duas espécies: $H$. brunnioides e $H$. psiadioides.

Hooker \& Arnott (1841), acrescentaram uma nova espécie ao gênero - Heterothalamus spartioides - para a flora da Argentina.

Weddel (1856), descreveu Heterothalamus boliviensis e, em 1865, H. acaulis, espécies posteriormente subordinadas aos gêneros Pseudobaccharis (Cabrera, 1944), Psila (Cabrera, 1955) e Baccharis (Cuatrecasas, 1967).

Para a Flora Brasiliensis, Baker (1882) citou três espécies de Heterothalamus, das quais apenas Heterothalamus psiadioides Less. continua válida; $H$. brunnioides Less. tornou-se sinônimo de $H$. alienus e $H$. spartioides foi excluída do gênero.

Com base em Marshalia aliena, descrita anteriormente por Sprengel (1826), Kuntze (1898) criou o binômio Heterothalamus alienus, subordinando $H$. brunnioides à sua combinação.

Para a flora do Uruguai, Arechavaleta (1898) reconheceu a ocorrência de Heterothalamus alienus (sob o nome $H$. brunnioides) e realizou a diagnose de $H$. psiadioides que, na época, ainda não havia sido coletada no país.

Lombardo (1964), reconheceu a existência de duas espécies para a flora uruguaia: Heterothalamus alienus, citado como elemento comum em cerros e serranias dos departamentos de Lavalleja e Maldonado, e H. psiadioides, considerado como espécie bastante rara, restrita ao Departamento de Tacuarembó.

$\mathrm{Na}$ descrição das espécies da subtribo Baccharinae Less. ocorrentes no Brasil (sob o nome Baccharidinae Hoffmann), Barroso (1976) reconheceu apenas duas espécies de Heterothalamus: H. alienus e $H$. psiadioides.

Para Giuliano (2000), o gênero, ditípico, conta com uma única espécie na Argentina Heterothalamus alienus - restrita às províncias fitogeográficas Chaquenha e do "Espinal" (Províncias de Córdoba, San Luis e La Rioja).

Para a flora de Santa Catarina, Barroso \& Bueno (2002) incluíram duas espécies de Heterothalamus, reconhecendo, na diagnose das mesmas, que os capítulos masculinos podem ou não apresentar flores radiais femininas ou neutras.

Deble, Oliveira \& Marchiori (2003), acrescentaram uma espécie nova ao gênero: Heterothalamus rupestris, endêmica da Serra do Sudeste no Rio Grande do Sul.

Hellwig (2003) considerou a existência de três ou quatro espécies para o gênero e descreveu uma espécie nova - Heterothalamus wagenitzii -, nativa na Serra Geral do Rio Grande do Sul e Santa Catarina.

Deble, Oliveira \& Marchiori (2004), com base em Heterothalamus wagenitzii Hellwig, descreveram um novo gênero para a subtribo Baccharinae: Heterothalamulopsis.

\section{MATERIAL E MÉTODOS}

O presente trabalho incluiu revisão bibliográfica, coleta de material botânico e análise de exsicatas conservadas nos seguintes herbários do sul do Brasil (Rio Grande do Sul, Santa 
Catarina e Paraná), Argentina e Uruguai: CNPO, Herbário da Embrapa Pecuária Sul (Bagé, RS); HBR, Herbário Barbosa Rodrigues (Itajaí, SC); HDCF, Herbário do Departamento de Ciências Florestais (Santa Maria, RS); ICN, Herbário do Departamento de Botânica, Universidade Federal do Rio Grande do Sul (Porto Alegre, RS); LP, Herbário do Museu de História Natural (La Plata, Argentina); MBM, Herbário do Museu Botânico Municipal (Curitiba, PR); MCPUC, Herbário do Museu de Ciências, Pontifícia Universidade Católica do Rio Grande do Sul (Porto Alegre, RS); MVFA, Herbário da Faculdade de Agronomia, Universidade de la Republica (Montevidéu, Uruguai); MVJB, Herbário do Jardim Botânico de Montevidéu (Uruguai); MVM, Herbário do Museu de História Natural de Montevidéu (Uruguai); PACA, Herbarium Anchieta (São Leopoldo, RS); PEL, Herbário do Departamento de Botânica, Universidade Federal de Pelotas (Pelotas, RS); SI, Herbário do Instituto de Botânica Darwinion (San Isidro, Argentina); SMDB, Herbário do Departamento de Biologia, Universidade Federal de Santa Maria (Santa Maria, RS); UPCB, Herbário do Departamento de Botânica, Universidade Federal do Paraná (Curitiba, PR).

As exsicatas foram revisadas nos próprios herbários; havendo necessidade, pediu-se empréstimo de material botânico. O material coletado foi anexado ao Herbário do Departamento de Ciências Florestais (HDCF); em caso de duplicatas, estas foram enviadas a outros herbários.

As descrições botânicas basearam-se principalmente em Baker (1882), Barroso (1976) e Deble, Oliveira \& Marchiori (2003, 2004). Os termos botânicos utilizados nas diagnoses constam no Dicionário de Botânica (Font Quer, 1982).

\section{RESULTADOS E DISCUSSÕES}

Chave para a separação dos gêneros da subtribo Baccharinae Less. na flora regional

1a. Capítulos femininos geralmente com o receptáculo desnudo; páleas, quando presentes, lineares e caducas. Flores femininas com corola tubuloso-filiforme de ápice truncado, dentado, laciniado ou raramente ligulado; pápus de cerdas persistentes (raro caducas), menores ou mais longas do que o tubo da corola .2

2a. Plantas monóicas. Capítulos com numerosas flores marginais femininas e 2-12 flores centrais masculinas Baccharidastrum Cabrera 2b. Plantas geralmente dióicas (capítulos apenas com flores femininas ou masculinas); em espécies monóicas ou polígamo-dióicas, sem o conjunto de caracteres acima

Baccharis L.

1b. Capítulos femininos com receptáculo paleáceo; páleas persistentes, oblanceoladas ou cimbiformes. Flores femininas com corola tubulosa, carnosa, e ápice distintamente ligulado; pápus de poucas cerdas rígidas e caducas na flor feminina, nunca mais longas do que o tubo da corola 3

3a. Plantas polígamo-dióicas ou imperfeitamente dióicas. Capítulos masculinos com flores heteromorfas, com 1-2séries de flores marginais liguladas e numerosas flores do disco com corola tubulosa de ápice dilatado, 5-lobado; pápus da flor masculina com cerdas caducas, filiformes e ápice encurvado, não dilatado. Aquênios 5-7-costados

.Heterothalamus Lessing 
3b. Plantas dióicas. Capítulos masculinos com flores isomorfas, todas de corola tubulosa com ápice dilatado e 5secto; pápus da flor masculina de cerdas persistentes, planas e ápice dilatado. Aquênios 10-costados Heterothalamulopsis Deble, Oliveira \& Marchiori

\section{O gênero Heterothalamulopsis Deble, Olivei- ra \& Marchiori}

Rev. Ciênc. Florestal, vol. 14, n. 1, p. 1-7, 2004.

O gênero Heterothalamulopsis foi concebido para abrigar uma espécie de Heterothalamus (H. wagenitzii Hellwig), descrita recentemente para a Serra Geral do Rio Grande do Sul e Santa Catarina, que não se insere de maneira satisfatória nesse gênero, requerendo análise mais ampla sobre seu posicionamento na subtribo Baccharinae Lessing.

As páleas persistentes e cimbiformes, a corola carnosa e distintamente ligulada, bem como o pápus escasso, com cerdas rígidas e caducas na flor feminina, excluem a espécie do gênero Baccharis L., sugerindo sua inclusão em Heterothalamus Lessing.

O caracter dióico, as brácteas involucrais obovadas, o pápus da flor masculina com cerdas persistentes, planas e de ápice dilatado, os aquênios 10-costados, a ausência de flores femininas ou neutras liguladas no invólucro masculino, bem como a cor branca das flores no capítulo masculino, são características que não encontram correspondência entre as espécies do gênero Heterothalamus Lessing.

As peculiaridades morfológicas de Heterothalamus wagenitzii Hellwig, demonstram a necessidade do reconhecimento de um novo gênero botânico, até o momento monotípico, criado especialmente para acomodar esta espécie singular na subtribo Baccharinae Lessing.
Etimologia: o nome Heterothalamulopsis compõe-se de Heterothalamus e do sufixo grego opsis, que significa "aspecto" ou "aparência", indicando a semelhança ou proximidade com o referido gênero.

Por se tratar de um gênero monotípico, incluiu-se, neste trabalho, apenas a descrição da espécie. Uma diagnose completa do gênero, bem como comentários e ilustrações evidenciando as diferenças morfológicas entre os gêneros Heterothalamus e Heterothalamulopsis, podem ser consultados em Deble, Oliveira \& Marchiori (2004).

Descrição de Heterothalamulopsis wagenitzii (Hellwig) Deble, Oliveira \& Marchiori

Rev. Ciênc. Florestal, vol. 14, n. 1, p. 1-7, 2004.

Bas.: Heterothalamus wagenitzii F. H. Hellwig, Haussknechtia 9, p. 135-139, 2003.

Subarbusto lenhoso, ramoso, com cerca de 0,2-0,8 (1) $\mathrm{m}$ de altura (Figura 1a). Folhas alternas, sésseis, glabras ou com poucos tricomas, escassamente pontuado-glandulosas, estreitamente lineares, íntegras, uninérvias, de ápice acuminado até mucronado, base atenuada, com 3-10 mm de comprimento e $0,2-0,5 \mathrm{~mm}$ de largura (Figura 1b). Capítulos sésseis ou breve pedunculados $(-1 \mathrm{~cm})$, em glomérulos terminais de 3-20 (25) capítulos (Figura 1a). Invólucro feminino hemisférico, de $2,5 \mathrm{~mm}$ de altura por 2-3 mm de diâmetro (figura 1e); brácteas involucrais 2-3-seriadas, de ápice obtuso ou truncado, com 1,5-2 $\mathrm{mm}$ de comprimento e 1 $\mathrm{mm}$ de largura (Figura 1e); flores cerca de 3050; corola com 1-1,2 mm de comprimento (Figura 1g); estigma pouco exserto ao tubo da corola, de aproximadamente $1,2 \mathrm{~mm}$ de comprimento, com ramas lanceoladas de ápice obtuso (Figura 1g); pápus breve, caduco, com cerdas planas, de margens irregulares e base geniculada, lineares até linear-lanceoladas, de 1 
$\mathrm{mm}$ de comprimento por $0,1-0,2 \mathrm{~mm}$ de largura (Figura 1g); pálea cimbiforme, de ápice triangular, obtuso ou truncado, com 2-2,5 mm de comprimento por 0,3-0,4 $\mathrm{mm}$ de largura (Figura 1f). Invólucro masculino campanulado, com 2-3 mm de altura e diâmetro (Figura 1c); brácteas involucrais 2-3-seriadas, de 1,5-2 mm de comprimento por $1 \mathrm{~mm}$ de largura, de ápice obtuso ou truncado (Figura 1c); flores cerca de 30 , isomorfas, masculinas; corola branca, tubulosa, de ápice dilatado e 5-secto, com 2-2,5 $\mathrm{mm}$ de comprimento (Figura 1d); rudimento do estigma pouco exserto ou exserto, de $2,5 \mathrm{~mm}$ de comprimento (Figura 1d); estames com filetes de 1 $\mathrm{mm}$ de comprimento e anteras com tecas de 0,8 mm de comprimento; pápus de cerdas brancas, persistentes, planas, de ápice curvo e dilatado, com $2 \mathrm{~mm}$ de comprimento (Figura 1d). Aquênio 10-costado, glabro, elíptico, levemente curvo, de 1-1,5 mm de comprimento por 0,2-0,3 mm de largura (Figura $1 \mathrm{~h}$ ).

TIPO - BRASIL: Rio Grande do Sul, Itaimbezinho p. São Francisco de Paula; in rupestribus dumetosis, planta feminina, 13. XI. 1953, B. Rambo, Herbarium Anchieta, Florae Brasiliae australis, 54.522. Holotypus B não visto, Isotypi PACA, HBR, Paratypus PACA.

Etimologia: o epíteto específico é uma homenagem ao botânico alemão Gerhard Wagenitz, nascido em 1927, na cidade de Potsdam. Assistente científico na Universidade de Berlim, curador do Jardim e Museu Botânico de Berlim, Wagenitz é professor da Universidade de Göttingen, desde 1969.

\section{Distribuição e Hábitat}

Heterothalamulopsis wagenitzii é endêmica da borda da Serra Geral, crescendo justamente nos "aparados da serra", em altitudes superiores a $900 \mathrm{~m}$. No estado do Rio Grande do Sul, a planta é rara, sendo conhecida apenas pela localidade típica, em Cambará do Sul. No estado de Santa Catarina, a mesma possui distribuição geográfica mais ampla, havendo coletas nos municípios de Bom Jardim da Serra, Bom Retiro, Grão Pará, São Joaquim e Ubirici. Dado a raridade e escasso interesse, a espécie carece de nomes populares.

\section{Material examinado}

BRASIL: RIO GRANDE DO SUL: Cambará do Sul, Itaimbezinho p. São Francisco de Paula, in rupestribus dumetosis, B. Rambo, 13. XI. 1953 (PACA 54.522, HBR 12.933); Itaimbezinho p. São Francisco de Paula, in rupestribus dumetosis, B. Rambo, 7. II. 1941 (PACA); Cambará p. São Francisco de Paula, in rupestribus dumetosis, B. Rambo, II. 1948 (PACA); Itaimbezinho, em borda de mata com araucária, J. A. Jarenkov \& R. M. Bueno 1181, 27. XII. 1988 (MBM 178.309, PEL); Fortaleza, borda do perau, arbusto de $1 \mathrm{~m}$, capítulos creme, G. Hatschbach \& O. S. Ribas, 24. XI. 1994 (MBM 170.245); Itaimbezinho, beira do paredão rochoso, capítulos imaturos, subarbusto de $60 \mathrm{~cm}$, L. P. Deble, A. S. de Oliveira \& J. N. C. Marchiori, 9. X. 2003 (PACA, HDCF, CNPO); Fortaleza, capítulos imaturos, L. P. Deble, A. S. de Oliveira \& J. N. C. Marchiori, 9. X. 2003 (HDCF, CNPO); L. P. Deble, A. S. de Oliveira \& J. N. C. Marchiori, flores creme, arbusto de $50 \mathrm{~cm}, 11$. X. 2003 (CNPO, PACA, HDCF); no paredão rochoso, arbusto de $50 \mathrm{~cm}$, exemplar feminino, L. P. Deble 558a, A. S. de Oliveira 634a \& J. N. C. Marchiori, 12. XI. 2003 (CNPO, PACA, HBR); subarbusto de $40 \mathrm{~cm}$, exemplar masculino, flores creme, L. P. Deble 558b, A. S. de Oliveira 634b \& J. N. C. Marchiori, 12. XI. 2003 (CNPO, PACA, HBR); Itaimbezinho, herba inter rupes ad rivum, A. Sehnen, 19. XII. 1950 (PACA 50. 967, SI).

SANTA CATARINA: Araranguá, Serra da Pedra, 1000 m, flor branca, R. Reitz 302, 28. XII. 1943 (HBR 853). Bom Jardim da Serra, beira do rio, perto da cidade, L. B. Smith \& R. Reitz 10.191, 16. I. 1957 (HBR 18.579); Serra do Oratório, $1400 \mathrm{~m}$, flor branca, R. Reitz \& R. M. Klein 7.677, 9. XII. 
1958 (HBR 22.816); Curral Falso, flor branca, R. Reitz \& R. M. Klein, 10. XII. 1958 (HBR 22.883); Curral Falso, $1500 \mathrm{~m}$, flor branca, arbusto de $30 \mathrm{~cm}$, R. Reitz \& R. M. Klein 8.157, 13. I. 1959 (HBR 22.718, LP); Beira do rio do Rastro, L. B. Smith \& R. M. Klein 15.784, 14. XII. 1971 (HBR 52.051, $\mathrm{SI}$ ); em paredão rochoso, arbusto de $80 \mathrm{~cm}$, flores creme, exemplar masculino, L. P. Deble 560a, A. S. de Oliveira 636a \& J. N. C. Marchiori, 5. XII. 2003 (ICN, HDCF), ibidem, subarbusto de $50 \mathrm{~cm}$, exemplar feminino, L. P. Deble 560b, A. S. de Oliveira 636b \& J. N. C. Marchiori, 5. XII. 2003 (ICN, HDCF). Grão Pará, Serra do Corvo Branco, paredão rochoso, capítulos creme, arbusto de $50 \mathrm{~cm}$, G. Hatschbach et al.,10. XII. 2000 (MBM 254.080, UPCB). Bom Retiro, Campo dos Padres, 1900 m, rupestre, flor branca, R. Reitz 2.386, 20. XII. 1948 (HBR 15.254), ibidem, R. Reitz 2.632 , 20. XII. 1948 (HBR 15.252). São Joaquim, Serra do Oratório, aparados da Serra, $1400 \mathrm{~m}$, arbusto de $1 \mathrm{~m}, \mathrm{~A}$. Lourteig 2.153, 14. XII. 1967 (SI). Ubirici, 1100 m, arbusto de $70 \mathrm{~cm}, \mathrm{G}$. Hatschbach \& O. S. Ribas, 17. II. 1995 (MBM 172.703).

\section{O gênero Heterothalamus Lessing}

Linnaea 5, p. 145, 1830 et 6, p. 503, 1831: A. P. de Candolle, Prodr. 5, p. 216, 1836: Baker in Martius F1. Bras. 6 (13), p. 17, 1882. (Tipo: Heterothalamus psiadioides Less.)

Compreende três espécies de subarbustos e arbustos polígamo-dióicos ou imperfeitamente dióicos (Figuras 2a, 3a, 4a). As folhas, alternas, uninérvias, pontuado-glandulosas e de margens inteiras, dentadas ou serradas na metade superior, são sésseis, concolores e geralmente glabras (Figuras 2b, 3b, 4b).

Os capítulos estão dispostos em corimbos terminais, menos comumente isolados no ápice ou axila dos ramos (Figuras 2a, 3a, 4a). O invólucro, campanulado nas plantas funcionalmente masculinas e hemisférico ou globoso nas plantas femininas, reúne brácteas involucrais dispostas em 3-4-séries (Figuras 2c, 2f, 3c, 3f, 4c, 4f).
O receptáculo pode ser plano ou cônico, com pontos de inserção das flores bem delimitados; é paleáceo nas plantas femininas, com páleas persistentes, oblanceoladas ou cimbiformes (Figuras $2 \mathrm{~g}, 3 \mathrm{~g}, 4 \mathrm{~g}$ ), e desnudo nas plantas funcionalmente masculinas.

As flores dos capítulos femininos são numerosas (130-350), carnosas, de coloração parda, amarelo-esverdeada, pardo-esverdeada ou pardo-amarelada. A corola, geralmente glabra (pilosa em $H$. rupestris), possui ápice curtoligulado e base dilatada ou não (Figuras 2h, 3h, 4h). O estigma, curto-exserto ou exserto ao tubo da corola, possui ramas de ápice lanceolado (Figuras 2h, 3h, 4h). O pápus, mais curto do que as flores, é caduco e com poucas cerdas rígidas, por vezes de base geniculada (Figuras 2h, 3h, 4h).

As flores do capítulo masculino são dimorfas. As marginais, de cor amarela, dispostas em uma ou duas séries, são femininas ou neutras, de tubo carnoso e lígula membranosa até carnosa (Figuras 2d, 3d, 4d); apresentam corola geralmente glabra (pilosa em $H$. rupestris), e pápus de poucas cerdas, curtas e caducas, de base geniculada ou não. As flores do disco são numerosas (cerca de 40-100) e tipicamente hermafroditas, porém masculinas por aborto do gineceu; possuem corola amarela, geralmente glabra, de ápice dilatado e 5-lobado (Figuras 2e, 3e, 4e); o rudimento do estigma, de ápice capitado, tem ramos curtos e geralmente separados (Figuras 2e, 3e, 4e); as anteras possuem tecas de ápice ovado-lanceolado e base obtusa; o pápus reúne poucas cerdas filiformes, caducas e de ápice curvo (Figuras 2e, 3e, 4e).

Os aquênios de 1 a $2 \mathrm{~mm}$ de comprimento, são cônicos, levemente curvos ou curvos e de epicarpo 5-7-costado, glabro ou papiloso (Figuras $2 \mathrm{i}, 3 \mathrm{i}, 4 \mathrm{i})$.

O gênero Heterothalamus possui distribuição geográfica pampeana ou páleo-insular, ocorrendo no centro da Argentina (províncias de Córdoba, San Luis, La Rioja e Santiago del Estero), no Uruguai (departamentos de Canelo- 
nes, Cerro Largo, Durazno, Florida, Lavalleja, Maldonado, Montevideo, Río Negro, Rivera, Rocha, Tacuarembó e Treinta y Tres) e no sul do Brasil (estados do Rio Grande do Sul e Santa Catarina).

Etimologia: o nome genérico é composto da palavra grega heteros (= distinto, diferente) e da palavra latina thalamus (= leito nupcial), em referência ao receptáculo das plantas masculinas e femininas, que são distintos.

\section{Chave para a separação das espécies de Heterothalamus:}

1a. Folhas oblongas, de margens serradas na metade superior, com 15-45 (60) $\mathrm{mm}$ de comprimento por 4-15 (20) mm de largura. Aquênios papilosos, com epicarpo 6-7-costado

\section{H. psiadioides}

1b. Folhas lineares, de margens inteiras ou 1-6dentada na metade superior, com 7-40 $\mathrm{mm}$ de comprimento por $0,7-1,5 \mathrm{~mm}$ de largura. Aquênios papilosos ou glabros, com epicarpo 5-costado. 2

2a. Folhas de margem inteira. Inflorescência em glomérulos de (1) 412 capítulos, geralmente com pedúnculos de 2-3 cm de comprimento. Invólucro feminino globoso, de $7-11 \mathrm{~mm}$ de diâmetro. Páleas do receptáculo cimbiformes, de (2,5) 3-4 mm de comprimento. Flores femininas glabras

\section{H. alienus}

2b. Folhas de margem inteira ou 1-6dentada na metade superior. Inflorescência em glomérulos de (1) 2-4 capítulos, geralmente sésseis ou curtopedunculados $(-1,5 \mathrm{~cm}$ de comprimento). Invólucro feminino hemisférico, de 4-6 mm de diâmetro. Páleas do receptáculo oblanceoladas, de $2-2,5 \mathrm{~mm}$ de comprimento. Flores femininas pilosas. H. rupestris
Descrição de Heterothalamus alienus (Sprengel) O. Kuntze

Gen. Plant. 3 (2), p. 158, 1898.

Bas.: Marshalia aliena Sprengel, Syst. Veg. 3, p. 446, 1826.

=Heterothalamus brunnioides Lessing, Linnaea 6, p. 504, 1831;

=Sterea romerilla D. Don, Mss. Baker.

Arbusto ramoso, com 1-5 m de altura (Figura 2a). Folhas com 7-20 (35) mm de comprimento por 0,7-1 $(1,5) \mathrm{mm}$ de largura, alternas, sésseis, lineares, glanduloso-pontuadas, uninérvias, geralmente glabras, de margens inteiras e ápice agudo (Figura 2b). Capítulos com pedúnculos de 0,5-3 cm de comprimento, em corimbos terminais de (1) 4-12 capítulos (Figura 2a). Invólucro feminino globoso, de 4-6 mm de altura por 7-11 mm de diâmetro (Figura 2f); brácteas involucrais 3-4-seriadas, com 2,5-3 mm de comprimento por $0,7-1 \mathrm{~mm}$ de largura, oblanceoladas, curvas, de ápice agudo (Figura 2f); flores cerca de 150-250 (350); corola de 1,5$2 \mathrm{~mm}$ de comprimento (Figura $2 \mathrm{~h}$ ); pápus de cerdas rígidas, caducas, com 1-1,5 mm de comprimento (Figura $2 \mathrm{~h}$ ); pálea cimbiforme, de $(2,5)$ 3-4 mm de comprimento por 0,3-0,4 mm de largura, de ápice triangular ou obtuso (Figura 2g). Invólucro masculino campanulado, com 3-4 mm de altura por 5-9 $\mathrm{mm}$ de diâmetro (Figura 2c); brácteas involucrais 3-seriadas, com 2-2,5 mm de comprimento e $1 \mathrm{~mm}$ de largura, lanceoladas e de ápice agudo (Figura 2c); flores cerca de 60-110 (Figuras 2d, 2e). Aquênio glabro, 5-costado, cônico, curvo, com 1,2-1,5 (2) mm de comprimento por 0,3-0,4 mm de largura (Figura 2i).

TIPO - BRASIL, Rio Grande do Sul, entre São Sepé e Cachoeira do Sul, Leg. F. Sellow d. 1673.

Etimologia: o epíteto específico está relacionado à palavra latina alienus (= que pertence a outro, alheio, estranho), referindo-se ao hábito particular desta espécie. 


\section{Comentários e Discussões}

Heterothalamus alienus difere das outras espécies do gênero por ser arbusto de até $5 \mathrm{~m}$ de altura, pelo tamanho e forma dos capítulos femininos, bem como pelas páleas cimbiformes.

Em indivíduos das partes mais altas da Serra Geral de Santa Catarina (São Joaquim e Bom Jardim da Serra), verificou-se a presença de tricomas glandulares em tufos, nos ramos e margens do limbo foliar. Mesmo sendo um caráter morfológico desconhecido para o restante do gênero, a análise do hábito, bem como da estrutura morfológica dos capítulos e flores, não recomendam, o reconhecimento de uma identidade infra-específica para a espécie.

\section{Distribuição e Hábitat}

Heterothalamus alienus é a espécie com distribuição geográfica mais ampla no gênero, ocorrendo nos estados do Rio Grande do Sul e Santa Catarina (Brasil), bem como em parte do Uruguai e centro da Argentina.

$\mathrm{Na}$ Argentina, a espécie está distribuída nas províncias de Córdoba e São Luis, estendendose até os limites com as províncias de Santiago del Estero e La Rioja. Ocorre em lugares serranos, em altitudes de 800 a mais de $1800 \mathrm{~m}$ (Capilla del Monte, Pampa de Achala), tornando-se o principal componente do "matorral serrano" ou "romerillal", uma vegetação arbustiva transicional entre a vegetação arbórea, das partes mais baixas e a vegetação de ervas das partes mais elevadas das "Serras de Córdoba".

No Brasil, sua distribuição geográfica inclui a Serra do Sudeste e parte da Campanha do Sudoeste (Rio Grande do Sul), sendo freqüente em altitudes compreendidas entre 100 e 500 m; encontra-se, igualmente, na Serra Geral dos estados do Rio Grande do Sul e Santa Catarina. Ocorre, ainda, na região litorânea dos dois estados sulinos, desde Rio Grande até Laguna.

No Uruguai, a espécie é elemento característico de lugares serranos, principalmente nos departamentos de Maldonado, Lavalleja e Flo- rida. Sua presença foi também assinalada para a região litorânea, desde Canelones até Rocha; seu limite ocidental encontra-se no departamento de Rio Negro.

A espécie floresce com intensidade nos meses de outubro e novembro, havendo floração menos intensa nos meses de fevereiro e março. No Uruguai, de acordo com a literatura e testemunho de herbários, a espécie floresce com intensidade nos dois períodos citados.

Nos vizinhos países de língua castelhana, a espécie é conhecida como "romerillo" ou "romerillo-del-campo". No Brasil, ela recebe os nomes populares de "alecrim", "alecrim-docampo" ou "alecrim-comum".

\section{Material examinado}

BRASIL: RIO GRANDE DO SUL: Bagé, estância três flores, estrada para a Pedra Grande, A. M. Girardi-Deiro et al., 18. XI. 1986 (CNPO); E. E. Fitotécnica - potreiro B, A. M. Girardi-Deiro, 22. IV. 1976 (CNPO); próximo a estância Olívio Martins, A. M. Girardi-Deiro et al., 11. IV. 1985 (CNPO); estância da viola, A. M. Girardi-Deiro \& Gonçalves, 21. XI. 1985 (CNPO); estrada para a Pedra Grande, A. M. Girardi-Deiro, 18. XI. 1986 (CNPO); perto da cidade, $1 \mathrm{~km}$ ao sul, R. M. Klein \& U. Pastore 11.927 (HBR 52.106); N. I. Matzenbacher, 19. XII. 1993 (ICN 103.639); I. Fernandes, Casa de Pedra, 03. XI. 1989 (ICN 90.883); Casa de Pedra, M. Sobral, XII. 1991 (PEL 20.662); Casa de Pedra, I. Fernandes \& J. Giachin, 02. XI. 1989 (ICN 92.466); ibidem, I. Fernandes \& J. Giachin, 02. XI. 1989 (ICN 92.467); Serrilhada, L. Mentz, 28. XI. 1992 (ICN 101.601); Casa de Pedra, Ritter, 03. XI. 1989 (ICN 92.464); ibidem, 03. XII. 1989 (ICN 92.465); reserva ambiental "Chico Mendes", L. P. Deble \& A. S. de Oliveira, 26. II. 2004 (CNPO, HDCF); em campo, próximo a entrada da cidade, 26. II. 2004, L. P. Deble \& A. S. de Oliveira (CNPO, HDCF). Bom Jesus, Dutra, 10. II. 1937 (ICN 15.443); B. Rambo, 06. I. 1947 (SI); B. Rambo, 02. VII. 1954 (PACA 51.881); L. P. Deble, A. S. de Oliveira \& J. N. C. Marchiori, 27. III. 2004 (HDCF, CNPO). Caçapava do Sul, 
Gruta do Segredo, G. Pabst 6.430 \& E. Pereira 6.603, 31. X. 1961 (LP, PEL 21.778); Guaritas, J. R. Stehmann, 13. X. 1985 (ICN 64.322); ibidem, solo pedregoso, D. Falkenberg, 12. X. 1985 (MBM 103.640); ibidem, P. Brack \& R. Rodrigues, 04. IV. 1996 (ICN 119.899); ibidem, em frutificação, L. P. Deble \& A. S. de Oliveira, 12. VII. 2003 (CNPO, HDCF); ibidem, 270m de alt., R. Wasum, 29. X. 1999 (MBM); Minas do Camaquã, R. Wasum, 12. XII. 1997 (MBM); ibidem, R. Wasum et al., 01. X. 1988 (MBM 125.422). Cachoeira do Sul, M. Sobral 2526, XI. 1983 (MBM 99.738). Cambará do Sul, Serra da Pedra, B. Rambo, 05. II. 1948 (ICN 16.372). Canela, Passo do Inferno, B. Rambo, 10. II. 1941 (PACA 4.860). Canguçu, Mina do Paredão, S. Miotto, 24. IV. 1982 (ICN 64.780). Caxias do Sul, criúva, no campo, L. Scur 670, 25. III. 2000 (MBM 260.076). Dom Pedrito, BR 290, em direção a Bagé, L. P. Deble \& A. S. de Oliveira, 27. V. 2003 (HDCF, CNPO). Encruzilhada do Sul, serro São Salvador, $500 \mathrm{~m}$ de alt., D. Falkenberg, 23. I. 1994 (MBM 202.686); D. Falkenberg, 23. XII. 1985 (ICN 82.004); D. Falkenberg, 23. IX. 1981 (PACA 68.682); L. M. Baptista, 10. XII. 1975 (ICN 30.435).

Guaíba, N. I. Matzenbacher 20. VI. 1975 (ICN 29.349). Lavras do Sul, M. L. Porto, 25. VII. 1982 (ICN 64.791); A. Sehnem, 11. II. 1971 (PACA 11.895). Pelotas, pedreira capão do leão, J. Gomes 352, 4. X. 1950 (PEL 852, SI); ibidem, J. Jarenkow \& E. N. Garcia, 12. XII. 1997 (PEL 18.430, MBM); ibidem, F. A. Beduhn et al., 15. IV. 1999 (PEL 20.742); L. Arzivenco, 14. XII. 1975 (ICN 88.256); I. Augusto, 29. I. 1941 (ICN 19.074); Schlichting, 18. IX. 1958 (PACA 63.101); Santo Amor, L. Teodoro, 07. I. 1950 (ICN 17.216, LP); ibidem (ICN 17.946); ibidem (ICN 32.155). Piratini, serra das asperezas, próximo a divisa com Pinheiro Machado J. Jarenkow 1437, 19. XI. 1989 (PEL 11.586). Rio Grande, M. M. Job, I. 1936 (ICN 31.804); beira da estrada, arbusto de $4 \mathrm{~m}$, L. P. Deble \& A. S. de Oliveira, 5. XI. 2003 (CNPO, HDCF). Santana da Boa Vista, M. Sobral, Esposito \& Jarenkow, XI. 1987 (ICN 81.499, PACA); G. P. Schenkel, 13. I. 1990 (ICN 95.220). Santana do Livramento, beira da estrada, cerca de $14 \mathrm{~km}$ da entrada da cidade, L. P. Deble, A. S. de Oliveira \& J. N. C. Marchiori, 03. IV. 2004 (HDCF, CNPO). São Francisco de Paula, B. Rambo, 02. VII. 1954 (PACA 4.367), B. Rambo, 02. VII. 1954 (PACA 36.359); L. Vitto, 28. I. 1991 (ICN 119.846); A. Senhem, 19. XII. 1950 (PACA 50.967). São Sepé, K. Hagelund, 02. XII. 1983 (ICN 69.681). "Serra do Sudeste", A. Krapovickas et al. (SI). Vacaria, B. Rambo, 13. I. 1947 (PACA 37.073); $14 \mathrm{~km}$ rumo a Bom Jesus, arbusto de flor amarelolimão, G. Pabst 6.319 \& E. Pereira 6.492, 25. X. 1961 (PEL 21. 864).

SANTA CATARINA: Bom Jardim da Serra, rodovia SC-438, $3 \mathrm{~km}$ do cidade, G. Hatschbach \& E. Barbosa, 18. IV. 1994 (MBM 167. 367); R. Reitz \& R. Klein 7.821, 11. XII. 1951 (HBR 22.878); entre a cidade e a beira do rio do rastro, D. Falkenberg, 08. XII. 1986(ICN 98.058); J. Eskuche 1.645, 27. I. 1971 (SI); beira do rio, L. B. Smith \& R. Reitz 10.216, 16. I. 1957 (HBR 18.595); a $1 \mathrm{~km}$ do centro da cidade, beira da estrada, exemplar feminino, L. P. Deble, A. S. de Oliveira \& J. N. C. Marchiori, 06. XII. 2003 (CNPO, HDCF); ibidem, exemplar masculino, L. P. Deble, A. S. de Oliveira \& J. N. C. Marchiori, 06. XII. 2003 (CNPO, HDCF). Lages, Passo do Socorro, flor passada, R. Reitz 6.540, 03. II. 1963 (HBR 31.478). Laguna, restinga perto da cidade, R. Reitz \& R. Klein, 10. XI. 1951 (HBR 14.664); formações compactas na restinga, arbusto de $1,70 \mathrm{~m}$, capítulos creme, G. Hatschbach, 16. X. 1971 (MBM 20.694, UPCB 9.611); estrada para a cidade de Tubarão, J. Lindman \& H. Hass, 17. VII. 1966 (MBM 10.272); arbusto de $2 \mathrm{~m}$, capítulos creme, G. Hatschbach \& E. Forero, 09. X. 1977 (MBM 57.557); acesso a cidade, A. Krapovickas \& C. L. Cristóbal, 24. I. 1982 (MBM 77.490). São Joaquim, arbusto de flor amarela, A. Lourteig 2.178, 14. XII. 1967 (HBR); Postinho, J. R. Mattos 4.085, 16. I. 1956 (HBR 14.142); Faxinal, R. Reitz 3.265, 29. I. 1950 (HBR 4.975 , SI); distrito de Pericó, campo de solo rochoso, arbusto de $1 \mathrm{~m}, \mathrm{G}$. Hatschbach, 9. XII. 2000 (UPCB 44.087); ibidem, G. Hatschbach, 11. XI. 2001 (UPCB 45.169); ibidem, G. Hatschbach 72.559, A. 
Cervi \& E. Barbosa, 10. XI. 2001 (MBM 266.624) beira do rio Pericó, arbusto de 3 m, L. P. Deble, A. S. de Oliveira \& J. N. C. Marchiori, 06. XII. 2003 (HDCF, CNPO), estrada, cerca de $1 \mathrm{~km}$ do rio Pericó, L. P. Deble, A. S. de Oliveira \& J. N. C. Marchiori, 06. XII. 2003 (HDCF, CNPO). Laguna, G. Hatschbach 40.975 et al., 12. XI. 1978 (SI);

ARGENTINA: CÓRDOBA: A. L. Cabrera 18.772, 31. XII. 1968 (SI); A. Burkart 7.544, 29. XII. 1935 (LP, SI); H. Selmabe 554, 1943 (LP 49.320); J. F. Lopez, s.n., s/ data (LP 4.146). Achiras, D. O. King 193, 13. XII. 1928 (LP 90.751). Alta Gracia, Santa María, J. H. Hunziker 1.284, 6. XII. 1945 (LP 72.132); M. Biraben 55, II. 1937 (LP 20.509). Anizacate, vecino río Anizacate, M. M. Job 2.871, 23. XI. 1950 (LP 673.871). Ascochinga, M. L. Giardelli 748, 13. XI. 1936 (LP 9.648). Capilla del Monte, Castellanos 102, I. 1933 (SI); A. P. Rodrigo 319, 01. II. 1936 (LP 4.143); ibidem, A. P. Rodrigo 319b (LP 4.143b); J. A. Castigliani 1.773, 16. XI. 1945 (LP 89.663).Capina, entre Santo Antonio e, A. P. Rodrigo 453, II. 1936 (LP 4.144).Carlos Paz, F. A. Ruig 19.915, 04. XII. 1958 (LP 905.504). Cordoba, $55 \mathrm{~km}$ ao sul de, H. A. Fabris 1.556, 07. XII. 1958 (LP). Cosquin, A. P. Rodrigo 20, 5. XI. 1929 (LP 61.189). Cruz del Eje, P. Boffa 1.095, 10. XII. 1958 (LP 901.105). Est Cuche, J. V. Pentzell, 25. XII. 1953 (SI 18.833). La Falda, M. M. Job 488, I. 1936 (LP 4.151). Las Cumbrecitas, F. A. Ruig 17.766, 27. XII. 1955 (LP 33.740). Los Cocos, P. Boffa 1.047, 5. XII. 1958 (LP 901.070); Sierra Chica, A. L. Cabrera 6.378, III. 1940 (LP 38841, ICN 31.806). Los Gigantes, A. L. Cabrera, 31. XII. 1967 (LP). Mina Clavero, H. A. Fabris 6.751, 10. I. 1967 (LP). "Pampa de Achala", a $2.600 \mathrm{~m}$ de alt., J. H. Hunziker 6.420, 14. XII. 1945 (LP 72.355); J. H. Hunziker 1.410, 14. XII. 1945 (LP 72.133, SI); J. H. Hunziker 6.420, 13. XII. 1945 (LP 57.997); J. V. Pentzell 15.222, 25. III. 1944 (SI); F. Kurtz 15.590, I. 1981 (SI); O. Boelcke et al., 16. XII. 1973 (SI 15.885). “Pampa de Córdoba”, A. Ragonese 6.195, 27. XI. 1947 (LP 77.104); s/leg., V. 1977 (SI 4.247). Pocho, sierras, A. L. Cabrera et al., 14. X. 1978 (SI 29.643). Puerto Velez, A. Krapovickas 6.483, XI. 1949 (LP 302.342). Pueyseguir, R. Jansen 794 \& R. Sarandon, 27. I. 1908 (SI 9.172); ibidem, II. 1909 (SI 9.171). Punilla, vecino al lago San Roque, H. T. Hunziker 6.359, 9. XII. 1945 (LP 72.479); na subida para o "pampa de Achala", 1.700m, A. L. Cabrera
16.576 \& O. Solbrig, 21. II. 1965 (LP); M. M. Job, 18. VIII. 1952 (LP 905.065); H. A. Fabris 1.038, 20. II. 1955 (LP 899130). San José, s/leg., s/data (LP 4.149). San Roque, alrededores del Lago, J. H. Hunzikier 6.359, 9. XII. 1945 (LP 57.998). San Steban, E. G. Nicora 1.607, 6. I. 1938 (LP 61186). "Sierras de Córdoba", E. Nicora, 1936 (SI 19565); M. L. Giardelli 748, 13. XI. 1936 (SI); E. Nicora, 18. XII. 1937 (SI 17.777); Basttett, 20. III. 1943 (SI 20.113); C. Lizer 9.176, 1909 (SI). Salsipuedes, Dawson 105, III. 1938 (LP 18.111, ICN). Tanti, Sierras, A. Burkart 20.778, 5.XII. 1958 (SI); s/leg., II. 1944 (LP 72.385); entre Taninga e, A. Ragonese 9.286, 5. XII. 1958 (LP). Unquillo, G. Bruch, 1926 (LP 4.145). Villa Cura Brochero, A. L. Cabrera 20.392 \& R. Kiesling, 17. XII. 1969 (LP).

LA RIOJA: Arrieta et al. 1.152, 16. X. 1977 (SI).

SAN LUIS: El Volcán, M. A. Vignatti 79, I. 1934 (LP 4.150); M. A. Vignatti, II. 1933 (LP 4.184); s/ leg. 1. III. 1983 (SI 6.476). J. W. Gez, s/ leg., 12. I. 1922 (SI). San Luis, Castellanos, 21. XII. 1929 (LP 61.187); F. Devoto 187, s/data (LP 89.664). Santa Helena, C. Ezcurra \& L. M. Ponce 554 13. XII. 1989 (SI). San José del Morro, Sierra del Morro, R. Leal 19.886, 3. XI. 1958 (LP); ibidem, s/ leg., V. 1913 (SI).

URUGUAI: Cerro Paraná, Ruta 42 a 2 km del Rio Grande do Sul (Brasil), Bayce et al. 25. III. 1994 (MVFA 24.644). CERRO LARGO: Passo del Salso, Arroio Cordobez, s/ Leg., 3. X. 1961(MVFA 102); entre Villa Viñoles y La Zatea, P. Izaguirre et al. 21. X. 1992 (MVFA 21.071); quebrada camino, Sierra dos Ríos, s/ leg., 23. X. 1991. DURAZNO: Cerrezuela, cerca de Cantera de Arenisca, I. Grela et al., 16. I. 1998 (MVFA 27.603). FLORIDA: Cerro Colorado, São Pedro, Gallina et al. 5.038, 2. X. 1942 (MVM, MVFA, LP). LAVALLEJA: Minas, Colinas, J. Arechavaleta, 28. III. 1895 (MVM); Cerro Veronica, $400 \mathrm{~m}$ de alt., C. Osten 4.463, 14. IV. 1906 (MVM); Cerro del Penitente, G. Herter, 31. 11. 1912 (MVM 22.564); Cerro Verdum, M. Berro 820, VI. 1899 (MVFA); ibidem, M. Berro 6225, 1911 (MVFA); Cerro Arequita, A. Kaprovickas \& C. Cristóbal 16.174, 11. X. 1970 (LP); ibidem, H. Fabris \& F. Zuloaga 7.898, 11. X. 1970 (LP); ibidem, B. Rosengurtt 5.700, 03. IV. 1949 (MVM, MVFA, LP); ibidem, D. Legrand 4.290, 17. XII. 1953 (MVM); A. Lombardo 922, X. 1932 (MVJB); Abra 
de Zabaleta, C. Brussa, F. Rial \& N. Nicoli (MVJB 20.574); Est. Pororó, T. M. Pedersen 3.580 01. XII. 1955 (LP), Sierra de la Lorencita, D. Bayce et al., 26. III. 1996 (MVFA 25.503), ibidem (MVFA 25.512). MALDONADO: Aígua, costato del camino, Ruta 39, a 1,8 km de ruta 8, Rabaiotti et al., 15. XII. 1994 (MVFA 24.293); A. Lombardo 6.417; X. 1970 (MVJB); A. Lombardo 5.336, IX. 1954 (MVJB). Maldonado, Abra Perdomo, A. Cabrera 10.606, 9 XI. 1947 (MVM, LP); Sierra Ballena, J. Chebataroff 6.410 (LP); Arrilaga, 12. X. 1956 (MVFA); Balneário Solis, C. Osten 15.471 (MVM). Pan de Azúcar, entre Minas e, ruta 12, 12. X. 1963, P. Izaguirre \& Brescia 1.598 (MVFA); Quebrada de Los Cuervos, Brescia \& Marchesi 3.775, 18. XII. 1964 (MVFA); Cerro de las Lozas, M. Berro 6.928, 27. III. 1907; perto do $\mathrm{km} \mathrm{93,} 12 \mathrm{~km}$ a oeste, Mirador Nacional, H. Bartlett 21.310 (LP); B. Rosengurtt 1.861, 18. V. 1937 (LP); A. Lombardo 1.238, XI. 1932 (MVJB 10.576); C. Osten 5.520, 30. III. 1911 (SI); Sierra de las animas, XII. 1937, A. Lombardo 3.141 (MVJB); ibidem, s/leg. 25. 08.1897 (LP); ibidem, Marchesi 280, s/data (MVFA 563); ibidem, Gibert 845, I. 1869 (MVM); ibidem, G. Mato, IX. 1934, (MVM 10.292); in saxosis, Seijo, 28. III. 1885 (MVM); J. Arechavaleta, XI. 1908 (MVM). Piriápolis, C. Osten 5.520, 30. III. 1911 (MVM); A. Lombardo 1.207, VIII. 1928 (MVJB); E. C. Clos, 10. XII. 1933. San Carlos, M. Berro 3.597, 1906 (MVFA 3.597). MONTEVIDEO: Montevideo, F. Felippone 4.525, s/data (SI); W. Herter 5.299, II. 1927 (SI); Jnechart, XI. 1876 (LP). RIO NEGRO: loma pedregosa, E. Marchesi \& M. Vignale, 24. XI. 1995 (MVFA 25.272). RIVERA: Cuñapiru, B. Rambo 4.686, 12. I. 1941 (LP). Rivera, em ladera pedregosa, E. Marchesi et al., 30. X. 1997 (MVFA 27.430); al pie de paredones de arenisca, ruta 29, km 15, E. Marchesi \& I. Grela, XII. 1997 (MVFA 26.016). ROCHA: Rocha, A. Burkart 21.570, 22. II. 1960 (SI). TACUAREMBO: A. Lombardo 5.561, II. 1956 (MVJB). TREYTA Y TRES: Treynta y Tres, En la cima de la quebrada de Los Cuervos, D. Bayce et al. 26. III. 1996 (MVFA).
Descrição de Heterothalamus psiadioides Less. Lessing, Linnaea 6, p. 504, 1831;

A.P. de Candolle, Prodr. 5, p. 217, 1836;

Baker, in Martius Fl. Bras. 6 (3), p. 19, 1882.

=Baccharis czermakii Hochreut., Ann. Conserv. \& Jard. Bot. Genève 3 (27), p. 173, 1899, syn. nov.

Arbusto ramoso de 0,5-2 $\mathrm{m}$ de altura (Figura $3 a)$. Folhas de 15-45 (60) mm de comprimento por 4-15 (20) mm de largura, alternas, sésseis, glabras, oblongas, densamente glanduloso-pontuadas, uninérvias, de ápice obtuso, base cuneada e margem serrada na metade superior (Figura 3b). Capítulos com pedúnculos de 1-3 $\mathrm{cm}$ de comprimento, em corimbos terminais de (3) 6-12 capítulos (Figura 3a). Invólucro feminino hemisférico, de 3-4 $\mathrm{mm}$ de altura por 5-7 mm de diâmetro (Figura 3f); brácteas involucrais 4-seriadas, com 2-3 mm de comprimento por 0,5-1 mm de largura, oblanceoladas a oblongas, curvas e de ápice levemente agudo (Figura 3f); flores em número de $200-250$ por capítulo (Figura $3 \mathrm{~h}$ ); pálea oblanceolada ou ligeiramente cimbiforme, de 2,5 mm de comprimento por 0,2$0,3 \mathrm{~mm}$ de largura, de ápice curvo e triangular (Figura 3g). Invólucro masculino campanulado, com 3-4 mm de altura por 5-8 mm de diâmetro (Figura 3c); brácteas involucrais 3-seriadas, lanceoladas a oblanceoladas, de ápice agudo, com 1,5-2,5 mm de comprimento e 0,3-0,8 mm de largura (Figura 3c); flores cerca de 40-80 (Figuras 3d, 3e). Aquênio papiloso, 6-7-costado, cônico, curvo, com $1(1,5)$ mm de comprimento por 0,3 mm de largura (Figura 3i).

TIPO - BRASIL: Rio Grande do Sul, leg. F. Sellow, HIB. 958.

Etimologia: o epíteto específico compõem-se de psiadia (Psiadia Jacq., gênero africano de Asteraceae, pertencente à subtribo Baccharinae) e do sufixo grego oides (= com aspecto de). 


\section{Comentários e Discussões}

Heterothalamus psiadioides difere das demais espécies do gênero por possuir folhas oblongas, com margens serradas na metade superior, e pelos aquênios 6-7-costados.

\section{Distribuição e Hábitat}

Apesar da distribuição geográfica restrita, Heterothalamus psiadioides é relativamente abundante nos locais em que se encontra. É mais freqüente no estado do Rio Grande do Sul, onde foi assinalado para a Serra Geral (Cambará do Sul), Serra do Sudeste (Porto Alegre, Santana da Boa Vista, Canguçu e Camaquã) e Litoral. No estado de Santa Catarina, ela foi coletada apenas na restinga litorânea. No Uruguai, a espécie é rara, ocorrendo nos departamentos de Rivera, Tacuarembó e Treinta y Tres.

Heterothalamus psiadioides prefere solos rasos, ocorrendo, às vezes, em afloramentos rochosos úmidos, bem como em locais pouco iluminados, tais como a beira de matas, proximidade de grutas e paredões rochosos. É muito freqüente nos morros graníticos dos arredores de Porto Alegre, sendo elemento dominante em determinados locais.

Por observações pessoais de campo e segundo as anotações de etiquetas em exsicatas de herbário, pode afirmar-se que $H$. psiadioides floresce nos meses de outubro, novembro e dezembro. A espécie recebe os nomes populares de "alecrim-da-folha-larga" ou "vassoura".

\section{A Identidade de Baccharis czermakii}

Baccharis czermakii foi descrito por Hochreutiner (1899), com tipo procedente de Porto Alegre (RS). Apesar do local de procedência do tipo, a espécie não figura em nenhum trabalho sobre o gênero no Brasil. A descrição de Hochreutiner é pouco elucidativa; $B$. czermakii foi colocado pelo autor dentro da seção Angustifoliae Baker; a diagnose latina demonstra preocupação com as características vegetativas e o trabalho não oferece ilustração da nova espécie. O texto relata o local do tipo "campos pierreux des montagnes de la rua da Independência près de Porto Alegre"-, citando, na descrição: "floribus exteriores raro foemineis". Hochreutiner compara a espécie com Baccharis semiserrata e $B$. dracunculifolia, reconhecendo duas variedades: genuina e corymbosa. A análise do fotótipo, revela a sua identidade com Heterothalamus psiadioides; desse modo, Baccharis czermakii é reduzido, neste trabalho, à sinonímia de Heterothalamus psiadioides.

\section{Material examinado}

BRASIL: RIO GRANDE DO SUL: Arroio dos Ratos, T. M. Pedersen 11.989, 10. XI. 1977 (SI); K. Hagelung, 05. X. 1978 (ICN). Barra do Ribeiro, Alto Douradinho, J. Jarenkow 1.722, 9. X. 1990 (PEL 12.043, MBM). Camaquã, D. Falkenberg, 23. IX. 1985 (PEL 12.111, ICN, MBM, PACA). Canguçu, arbusto de $1 \mathrm{~m}$ de alt., em afloramento rochoso, flores amarelas, L. P. Deble, A. S. de Oliveira \& J. N. C. Marchiori, 5. XI. 2003 (HDCF, CNPO). Cerro Grande do Sul, J. Jarenkow 3.540, 28. IX. 1997 (PEL 18.300). Encruzilhada do Sul, A. Sehnem, 11. IX. 1971 (PACA); Lindeman et al., 9. X. 1972 (ICN). Guaíba, I. Boldrini, 13. X. 1980 (ICN); Matzenbacher, 19. X. 1980 (ICN); S. Boechat, 24. X. 1981 (ICN); R. P. Bueno, 5. XI. 1981 (ICN); Jesen \& Bauermann, 12. XI. 1983 (ICN); A. Zanin, 4. X. 1986 (ICN). Montenegro, Pinhal, A. Sehnem, 3.954, 26. X. 1949 (SI); ibidem, 20. XI. 1950 (SI). Morro Redondo, cerca de 5- $6 \mathrm{~km}$ da cidade, em direção a Capão do Leão, J. Jarenkow, 15. X. 1989 (PEL, MBM). Pelotas, I. Teodoro 180, 30. IX. 1954 (SI); Pedreira Capão do Leão, I. Teodoro 353, 04. X. 1954 (SI); ibidem, J. Gomes 353, 4. X. 1950 (PEL, LP); J. Sacco, 30. IX. 1954 (ICN, PEL); J. Sacco, 17. IX. 1958 (PACA); Capoeira, Horto Florestal, J. Sacco, 09. VI. 1959 (ICN, HBR, PEL). Porto Alegre, Morro da Polícia, I. Teodoro, 26. VIII. 1939 (ICN); Morro Santana, J. Mattos, 28. IX. 1956 (MBM); J. Mattos, 03. I. 1959 (UPCB);W. Rau, 02. XI. 1936 (LP); W. Rau, I. 1939 (SI); Vila Manresa, B. Rambo, 22. IX. 
1950 (PACA, SI); ibidem, B. Rambo, 02. VII. 1954 (PACA); Morro Santana, B. Rambo, 2. VI. 1954 (PACA); ibidem, 2. VII. 1954 (PACA); Morro da Polícia, 20. IX. 1948, B. Rambo (PACA, SI); Morro da Glória, B. Rambo, X. 1944 (LP); ibidem, B. Rambo, 10. X. 1945 (LP); ibidem, B. Rambo, 02. XI. 1931 (LP); Rambo, 1. XI. 1957 (PACA); Morro Santa Teresa, G. Pabst 4.591, 24. X. 1958 (LP); A. G. Ferreira, 6. XI. 1967 (ICN); Teresópolis, M. Fleig, 30. X. 1976 (ICN); Morro Santana, P. Sander et al., 13. I. 1985 (ICN); Morro do Osso, R. S. Rodrigues, 15. 09. 1995 (ICN). São Francisco de Paula, Itaimbezinho, A. Sehnem 5.145, 19. XII. 1950 (SI); Itaimbezinho, B. Rambo, 2. VII. 1954 (PACA); B. Rambo, 08. IV. 1955 (PACA); A. Girardi \& M. L. Porto, 03. XII. 1971 (ICN); Arbusto de $80 \mathrm{~cm}$ de alt., beira do penhasco, flores amarelas, L. P. Deble, A. S. de Oliveira \& J. N. C. Marchiori, 12. XI. 2003 (HDCF, CNPO). Santana da Boa Vista, arbusto de flores amarelo-claras, M. Sobral et al., IX. 1985 (ICN, MBM); J. Jarenkow \& M. Sobral, 10. X. 1987 (PEL 9.874, PACA); arbusto de 1,5 m de alt., beira do mato, flores amarelas, L. P. Deble, A. S. de Oliveira \& J. N. C. Marchiori, 5. XI. 2003 (HDCF, CNPO); ibidem, arbusto de 1,2 m, L. P. Deble, A. S. de Oliveira \& J. N. C. Marchiori, 5. XI. 2003 (HDCF, CNPO). São Leopoldo, Morro das Pedras, I. Teodoro, 26. XI. 1939 (ICN). Torres, B. Irgang et al. 15. VII. 1972 (ICN). Sentinela do Sul, $5-10 \mathrm{~km}$ de Araçá (RS), Jarenkow 3.164, 5. X. 1996 (PEL 16.743). Viamão, arbusto de $1,5 \mathrm{~m}$, no campo, $M$. Sobral \& P. Brack, IX. 1983 (MBM).

SANTA CATARINA: Garopaba, R. Klein \& A. Bressolin, 9.226, 18 XI. 1970 (HBR). Imbituba, Itapiruba, G. Hatschbach \& C. Zardini, 12. II. 1978 (MBM, LP). Laguna, restinga litorânea, R. Reitz \& R. Klein, 10. XI. 1951 (MBM, UPCB, LP, PACA); D. Falkenbrg, 02. X. 1993 (PEL, MBM, UPCB).

URUGUAI: RIVERA: Rivera, Al pie de paredones de arenisca ruta $29, \mathrm{~km} 15$. Chato dorado, E. Marchesi, I. Grela, XII. 1997 (MVFA 27.177); Gruta de piria, cuchilla negra, M. Bonifacino, M.
Catlaneo, L. Profuma, 15. XI. 1996(MVFA 26.016). TACUAREMBÓ: Tacuarembó, Valle Eden, Junto a garganta pedregosa, J. Chebattaroff, XII. 1940 (MVJB 10.579, LP). TREINTA Y TRES: Santa Clara de Olymar, 2 léguas de, B. Rosengurtt 4.838, 10. X. 1945 (LP); ibidem, Caraja del Olimar, B. Rosengurtt 4.838b, 10. X. 1945 (LP).

Descrição de Heterothalamus rupestris Deble, Oliveira \& Marchiori

Rev. Ciênc. Florestal, vol. 13, n. 2, p. 1-5, 2003.

Subarbusto com cerca de 0,5-1 $(1,5) \mathrm{m}$ de altura, ramoso desde a base (Figura 4a). Folhas com 10-30 mm de comprimento por 1-1,5 mm de largura, alternas, sésseis, glabras, lineares, densamente glanduloso-pontuadas, uninérvias, de ápice agudo, base atenuada e margem inteira ou com 1-6 dentes na parte superior (Figura 4b). Capítulos com pedúnculos de $0,5-1,5 \mathrm{~cm}$ de comprimento, em corimbos terminais de (1) 34 capítulos (Figura 4a). Invólucro feminino hemisférico ou globoso (quando imaturo), de 3$4 \mathrm{~mm}$ de altura por 4-6 $\mathrm{mm}$ de diâmetro (Figura 4f); brácteas involucrais 3-4-seriadas, de 2-2,5 $\mathrm{mm}$ de comprimento por $1 \mathrm{~mm}$ de largura, oblanceoladas, curvas e de ápice agudo (Figura 4f); flores cerca de 130-180 (Figura 4h); pálea oblanceolada, de 2-2,5 mm de comprimento por 0,3-0,5 mm de largura, com ápice triangular a truncado (Figura 4g). Invólucro masculino campanulado, de 3-4 mm de altura por 5-7 mm de diâmetro (Figura 4c); brácteas involucrais 3seriadas, de 2-2,5 mm de comprimento e 0,5$0,7 \mathrm{~mm}$ de largura, lanceoladas de ápice agudo a acuminado (Figura 4c); flores cerca de 60-80 (Figura 4d, 4e). Aquênio papiloso, 5-costado, cônico, levemente curvo, de ápice e base truncadas, com 1-1,5 mm de comprimento por 0,4-0,5 mm de largura (Figura 4i).

TIPO - BRASIL: Rio Grande do Sul, Caçapava do Sul, Guaritas, em afloramento rochoso, leg. L. P. Deble 499 \& A. S. de Oliveira 575 (12.VII. 2003) Holotypus SI, Isotypi CNPO, ICN, MBM, PACA, SMDB. 
Etimologia: do latim rupes (= rocha, rochedo), uma referência dos autores ao hábitat da espécie, que é exclusiva de afloramentos rochosos na Serra do Sudeste do Rio Grande do Sul.

\section{Comentários e Discussões}

O material desta espécie estava identificado, nos herbários, sob o nome de $H$. alienus, espécie com a qual se assemelha superficialmente, posto que ambas possuem folhas lineares. $H$. rupestris difere, todavia, de $H$. alienus, por ser um subarbusto ramoso desde a base, com cerca de $0,5 \mathrm{~m}$ de altura, pelas folhas mais longas, por vezes de margem 1-6-dentada, pela distribuição das pontuações glandulares no limbo foliar, pelos capítulos femininos menores e em número reduzido na inflorescência, e pelas páleas menores e oblanceoladas.

Heterothalamus rupestris se aproxima de $H$. psiadioides pelas folhas com pontuações glandulares distribuídas uniformemente no limbo foliar, bem como pela presença de páleas oblanceoladas. Ao contrário de H. psiadioides, H. rupestris difere pelo menor número de flores no capítulo feminino, pelo número de nervações dos aquênios e pelas folhas lineares.

\section{Distribuição e Hábitat}

Heterothalamus rupestris tem distribuição restrita à Serra do Sudeste do Rio Grande do Sul, principalmente na região entre Bagé e Caçapava do Sul, onde pequenas populações são freqüentemente observadas. Embora mais rara, ocorre em outros pontos do estado, como em Arroio dos Ratos, Encruzilhada do Sul, Santana da Boa Vista, Canguçu e Guaíba.

Heterothalamus rupestris é registrado com maior freqüência em afloramentos rochosos úmidos, nas proximidades de matas e cursos d'água, por vezes em simpatria com $H$. alienus e H. psiadioides.
A espécie não foi registrada para o Uruguai, até o momento, podendo, todavia, vir a ser encontrada, principalmente nas proximidades da fronteira com o Rio Grande do Sul.

De acordo com o material armazenado em herbário e observação pessoal de campo, a espécie floresce em pleno inverno, nos meses de junho, julho e agosto.

A planta é conhecida regionalmente pelo nome de "alecrim-da-pedra", "alecrim-rasteiro" ou "alecrim-do-inverno".

\section{Material examinado}

BRASIL: RIO GRANDE DO SUL: Arroio dos Ratos, K. Hagelung, 15. X.1981 (ICN). Bagé, Casa de Pedra, sobre afloramento rochoso, I. Fernandes \& J. Giachin, 30. VI. 1991 (ICN); ibidem, I. Fernandes \& J. Giachin, 29. VI. 1991 (ICN); Rincão do Inferno, sobre afloramento rochoso, L. P. Deble 500 \& A. S. de Oliveira 576, 27. VII. 2003 (CNPO); Pedra Grande, sobre afloramento rochoso, A. M. Girardi-Deiro et al., 17. XI. 2000 (CNPO); ibidem, A. M. Girardi-Deiro et al., 12. VII. 2001(CNPO); BR 153, M. Sobral, J. N. Marchiori \& S. Bordignon, VIII. 1987 (MBM, ICN), BR 153, KM 84, M. Sobral \& Grabauska, VI. 1985 (MBM, ICN). Caçapava do Sul, Guaritas, M. L. Porto, B. Irgang et al., 30. V. 1976 (ICN); ibidem, sobre afloramento rochoso, L. P. Deble 499 \& A. S. de Oliveira 575, 12. VII. 2003 (SI, ICN, PACA,CNPO), ibidem, arbusto ramoso, capitulos amarelos, L. P. Deble 501 \& A. S. de Oliveira 577, 12. VII. 2003 (MBM, HDCF). Canguçu, sobre afloramento rochoso, arbusto ramoso de 50 $\mathrm{cm}$, em frutificação, L. P. Deble, A. S. de Oliveira \& J. N. C. Marchiori, 5. XI. 2003 (HDCF). Encruzilhada do Sul, sobre afloramento rochoso, A. Sehnem, 11. IX. 1971 (PACA 12427). Guaíba, Fazenda São Maximiliano, sobre solo pedregoso, N. I. Matzembacher, 26. I. 2001 (ICN); ibidem, R. S. Rodrigues, 12. VII. 1995 (ICN). 


\section{Espécies excluídas ou sinonimizadas:}

$\mathrm{Na}$ literatura, bem como em etiquetas de herbário, foram encontrados quatro binômios, que requerem os comentários expostos a seguir.

1. Heterothalamus boliviensis Weddel-Espécie do sul do Peru, Bolívia, norte do Chile e noroeste da Argentina (Jujuy e Salta). Compreende subarbustos dióicos, que apresentam capítulos femininos com páleas oblanceoladas, levemente curvas e caducas, de flores carnosas e curto-liguladas. A análise de exsicatas da espécie (SI, LP) demostra que as brácteas involucrais obovadas e viscosas, o pápus ereto, caduco e de base geniculada da flor feminina, bem como o pápus persistente e com ápice dilatado da flor masculina, são também encontradas no gênero Heterothalamulopsis; cabe salientar, todavia, que os aquênios pilosos e 5-costados, assim como as páleas caducas, demonstram relação com algumas espécies de Baccharis. Desta maneira, parece conveniente o critério estabelecido por Cabrera (1975), que subordinou a espécie ao gênero Baccharis.

2. Heterothalamus czermakii - Nome não publicado, registrado em etiquetas de herbário. Trata-se de uma combinação, tendo por base Baccharis czermakii, espécie colocada, neste trabalho, na sinonímia de Heterothalamus psiadioides.

3. Heterothalamus macrophyllus Hieron. Espécie duvidosa, com tipo procedente do Rio de Janeiro. A análise do fotótipo não é elucidativa, visto que o material não exibe estruturas florais.

4. Heterothalamus minutiflora-Nome criado por L. Smith e registrado em etiquetas de herbário (SI); trata-se, na verdade, de Heterothalamulopsis wagenitzii.

\section{BIBLIOGRAFIA}

Arechavaleta, J. Flora Uruguaya. In: Anales del Museo Nacional de Montevideo. V. 6, p. 212216, 1898.

Baker, J. Compositae III. Asteroidae in Martius: Flora Brasiliensis, 6 (3) :1882.

Barroso, G. M. Compositae - Subtribo Baccharidinae Hoffmann - Estudo das espécies ocorrentes no Brasil. Rodriguésia, Rio de Janeiro, $\mathrm{n}^{\circ} 40,1976$, $281 \mathrm{p}$.

Barroso, G. M., Bueno, O. Compostas, Subtribo Baccharidinae. In: Reitz, P. R. Flora Ilustrada Catarinense, Itajaí, p. 765-1065, 2002.

Cabrera, A. L. Compuestas argentinas nuevas o interessantes. Notas del Museo de La Plata, La Plata, Tomo 2, p. 175-177, 1937.

Cabrera, A. L. Compuestas Sudamericanas nuevas ou críticas, Notas del Museo la Plata, La Plata, Tomo 9, n. 46, p. 249-254, 1944.

Cabrera, A. L. La identidad del genero Psila Philippi, Bol. Soc. Argentina Bot., 5, n. 4, p. 209-211, 1955.

Cabrera, A. L., Compuestas Sudamericanas críticas, Bol. Soc. Argentina Bot., 16, p. 256, 1975.

Cuatrecasas, J. Revision de las especies colombianas del genero Baccharis, Rev. Acad. Colomb. Cienc. Exact. Fis Nat. 13, n. 49, 1967.

Deble, L. P., Oliveira, A. S., Marchiori, J. N. C. Heterothalamus rupestris, espécie nova de Asteraceae do Rio Grande do Sul. Ciência Florestal, Santa Maria, vol. 13, n. 2, p. 1-5, 2003.

Deble, L. P., Oliveira, A. S., Marchiori, J. N. C. Heterothalamulopsis, gênero novo da subtribo Baccharinae Lessing (Astereae-Asteraceae). Ciência Florestal, Santa Maria, vol. 14, n. 1, p. 17, 2004.

Giuliano, D. A. Subtribu Baccharinae, in: A. T. Hunziker, Flora Fanerogamica Argentina 66, p. 1-69, 2000.

Giuliano, D. A. Classificación infragenérica de las especies argentinas de Baccharis (AsteraceaeAstereae). Darwiniana, San Isidro, vol. 39 (12), 2001. 
Hellwig, F. H. Taxonomy and evolution of Baccharidinae (Compositae). In: D. J. N. Hind \& H. J. Beentje Compositae: Systematics. Proceedings of the internacional Compositae Conference, Kew, 1994. Vol. 1, p. 575-590. Royal Bot. Gardens, Kew, 1996.

Hellwig, F. H. Heterothalamus wagenitzii (Compositae-Astereae), a new species from Brazil. Haussknechtia, 9, p. 135-139, 2003.

Heywood, V. H., Harbone, J. B. Hochreutiner, Énumération critique des plantes du Brésil Méridional. Ann. Conserv. \& Jard. Bot. Genève 3, n. 27, p. 173, 1899.

Hooker, W. J., Arnott, G. A. W. Contributions towards a Flora of South America and the island of the Pacific. J. Bot. (Hooker) 3, p. 21, 1841.

Kuntze, O. Generum Plantarum, p. 158, 1898.

Lessing, C. F. Synanthereae. Linnaea 6, 1831.
Linnaeus, C. Genera Plantarum, ed. 5: 370, 1754. Lombardo, A. Flora arborea y arborescente del Uruguay. Montevideo: Conceja Departamental, 1964. 105 p.

Nesom, G. L. Baccharis sect. Baccharidastrum (Compositae-Astereae), including two monoecious and one dioecius species. Phytologia 65 n. 3, p. 169-173, 1988.

Nesom, G. L. infrageneric taxonomy of North and Central American Baccharis (AsteraceaeAstereae). Phytologia 68, n. 6, p. 40-46, 1990.

Nesom, G. L. Subtribal classification of the Astereae (Asteraceae). Phytologia 76, n. 3, p. 193-274, 1994.

Sprengel, C. Sistema Vegetalibium 16, p. 445-446, 1826.

Weddel, H. A. Chloris Andina, Subtribus IX Baccharideae, p. 167-180, 1856. 


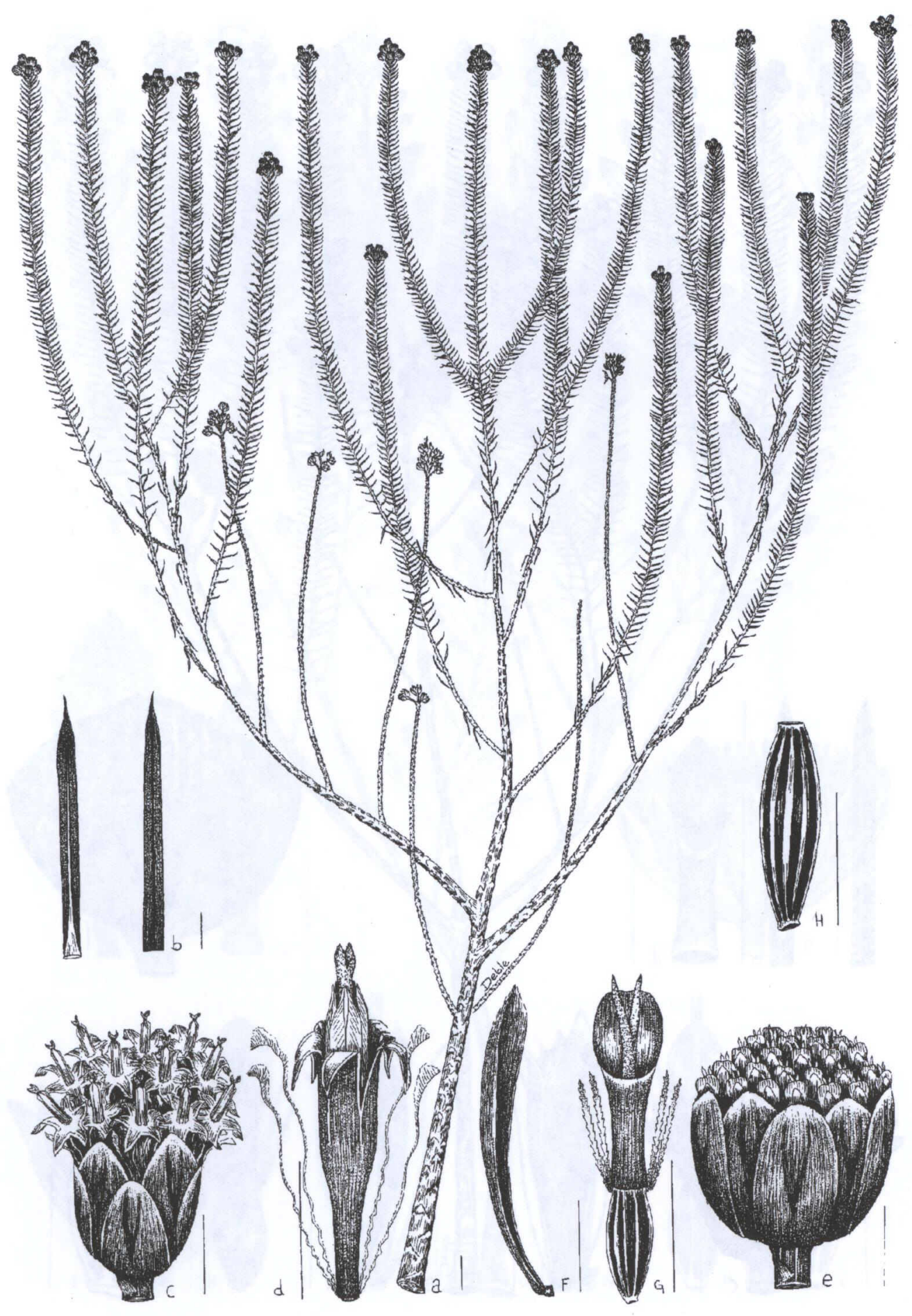

FIGURA 1 - Ramo feminino de Heterothalamulopsis wagenitzii (a). Folhas (b). Capítulo masculino (c). Flor masculina (d). Capítulo feminino (e). Pálea do receptáculo (f). Flor feminina com aquênio imaturo (g). Aquênio (h). Escala a = $1 \mathrm{~cm} ; \mathrm{b}, \mathrm{c}, \mathrm{d}, \mathrm{e}, \mathrm{f}, \mathrm{g}, \mathrm{h}=1 \mathrm{~mm}$. 


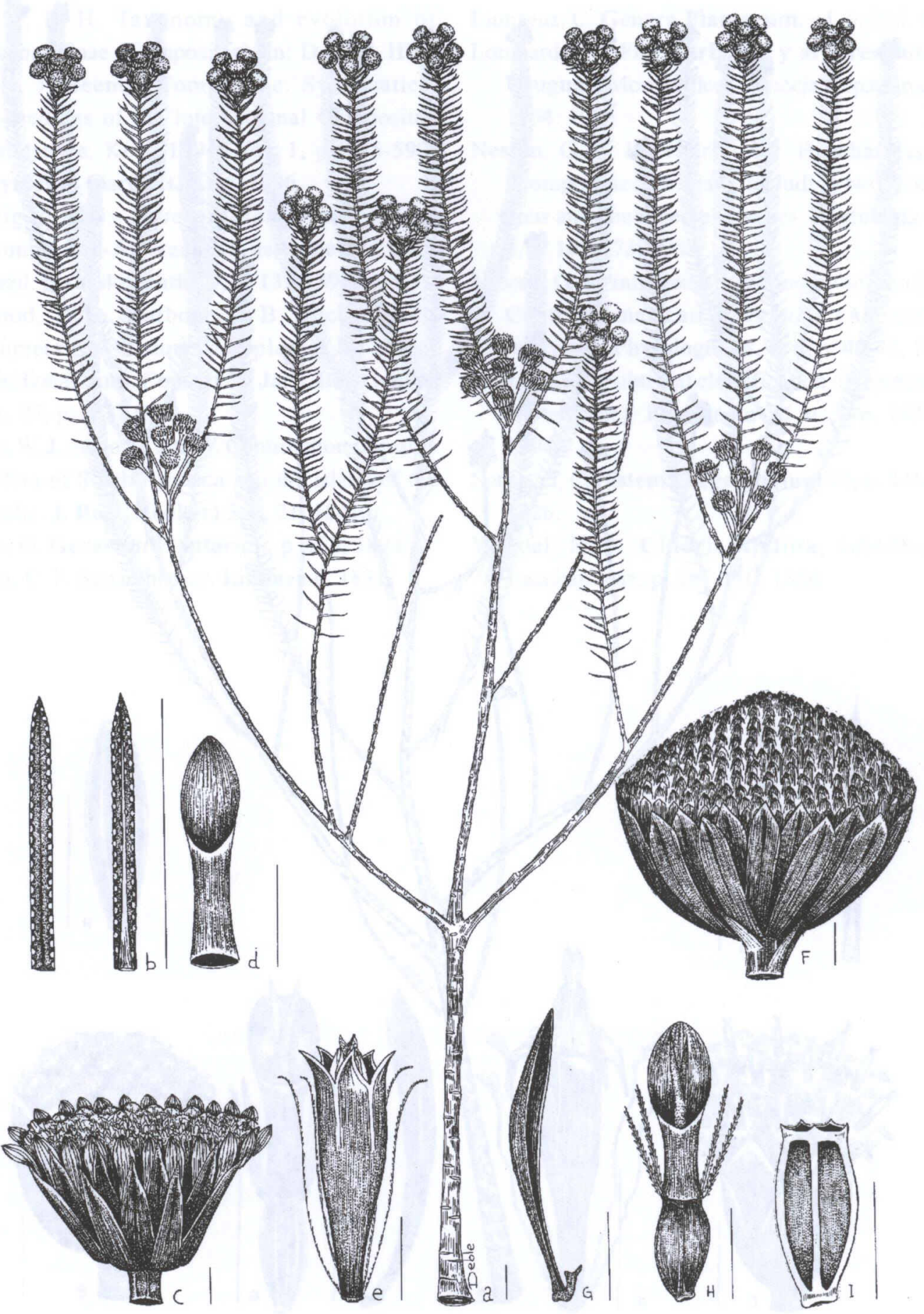

FIGURA 2 - Ramo feminino de Heterothalamus alienus (a). Folhas (b). Capítulo masculino (c). Flor neutra com rudimento do ovário retirado (d). Flor masculina (e). Capítulo feminino (f). Pálea do receptáculo (g). Flor feminina com aquênio imaturo (h). Aquênio (i). Escala a, b = $1 \mathrm{~cm}$; c, d, e, f, g, h, i = $1 \mathrm{~mm}$. 


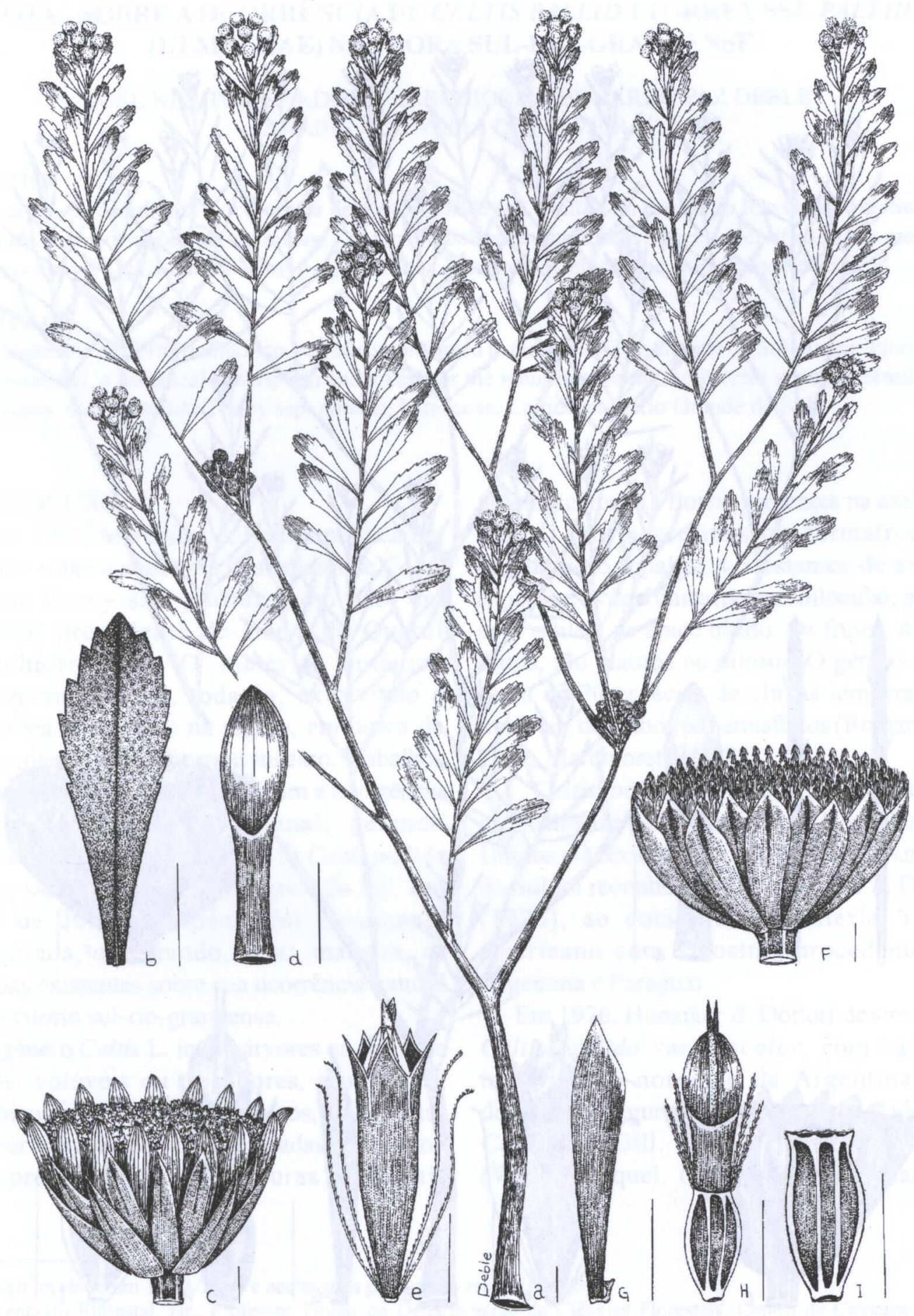

FIGURA 3 - Ramo feminino de Heterothalamus psiadioides (a). Folha (b). Capítulo masculino (c). Flor neutra com rudimento do ovário retirado (d). Flor masculina (e). Capítulo feminino (f). Pálea do receptáculo (g). Flor feminina com aquênio imaturo (h). Aquênio (i). Escala a, b = $1 \mathrm{~cm} ; \mathrm{c}, \mathrm{d}, \mathrm{e}, \mathrm{f}, \mathrm{g}, \mathrm{h}, \mathrm{i}=1 \mathrm{~mm}$. 


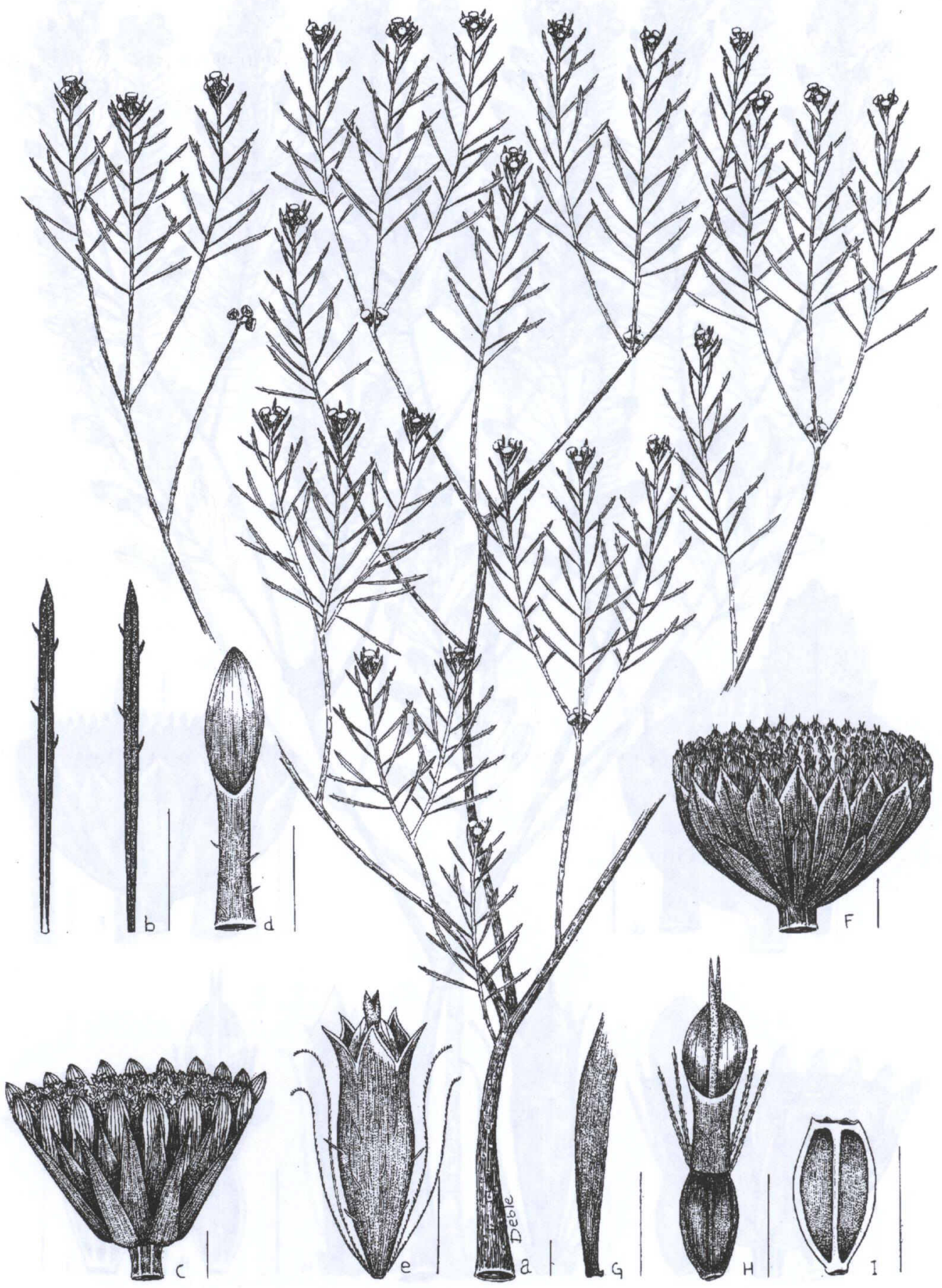

FIGURA 4 - Ramo feminino de Heterothalamus rupestris (a). Folhas (b). Capítulo masculino (c). Flor neutra com rudimento do ovário retirado (d). Flor masculina (e). Capítulo feminino (f). Pálea do receptáculo (g). Flor feminina com aquênio imaturo (h). Aquênio (i). Escala a, b=1 cm; c, d, e, f, g, h, i = $1 \mathrm{~mm}$. 